\title{
Spatial pattern evolution of Aedes aegypti breeding sites in an Argentinean city without a dengue vector control programme
}

\author{
Manuel O. Espinosa, ${ }^{1}$ Francisco Polop, ${ }^{1}$ Camilo H. Rotela, ${ }^{2}$ Marcelo Abril, ${ }^{1}$ \\ Carlos M. Scavuzzo² \\ ${ }^{1}$ Fundación Mundo Sano, Buenos Aires; ${ }^{2}$ Comisión Nacional de Actividades Espaciales, \\ Falda del Carmen, Córdoba, Argentina
}

\begin{abstract}
The main objective of this study was to obtain and analyse the space-time dynamics of Aedes aegypti breeding sites in Clorinda City, Formosa Province, Argentina coupled with landscape analysis using the maximum entropy approach in order to generate a dengue vector niche model. In urban areas, without vector control activities, 12 entomologic (larval) samplings were performed during three years (October 2011 to October 2014). The entomologic surveillance area represented 16,511 houses. Predictive models for Aedes distribution were developed using vector breeding abundance data, density analysis, clustering and geoprocessing techniques coupled with Earth observation satellite data. The spatial analysis showed a vector spatial distribution pattern with clusters of high density in the central region of Clorinda with a well-defined high-risk area in the western part of the city. It also showed a differential temporal behaviour among differ-
\end{abstract}

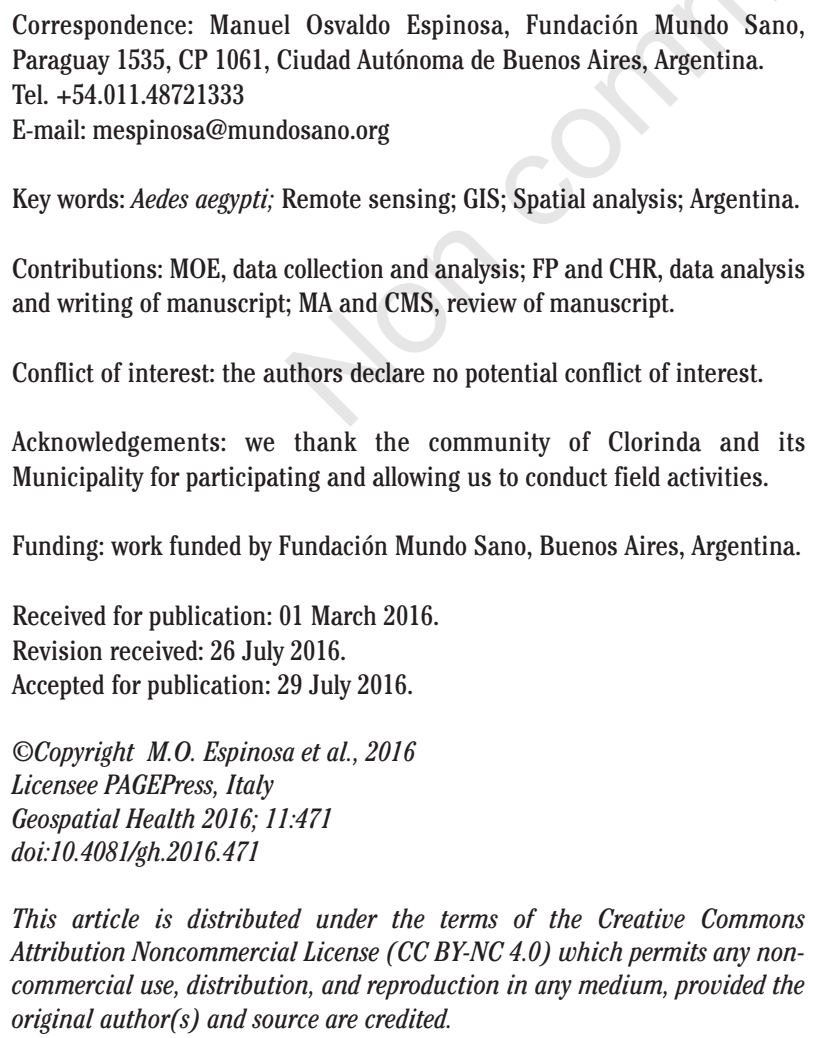

This article is distributed under the terms of the Creative Commons Attribution Noncommercial License (CC BY-NC 4.0) which permits any noncommercial use, distribution, and reproduction in any medium, provided the original author(s) and source are credited.

ent areas, which could have implications for risk models and control strategies at the urban scale. The niche model obtained for Ae. aegypti, based on only one year of field data, showed that $85.8 \%$ of the distribution of breeding sites is explained by the percentage of water supply (48.2\%), urban distribution (33.2\%), and the percentage of urban coverage (4.4\%). The consequences for the development of control strategies are discussed with reference to the results obtained using distribution maps based on environmental variables.

\section{Introduction}

According to the World Health Organization (WHO), dengue disease is one of the most widespread vector-borne diseases in the world (TDR/WHO, 2009). There are four different serotypes of dengue virus (DEN-1-4), all transmitted by mosquitoes of the species Aedes aegypti. In South America, this vector lives in urban areas (Gubler, 1997; Vezzani and Carbajo, 2008) with breeding habitats principally consisting of water-holding containers kept outside without covers. Ae. aegyp$t i$ is characterised by its adaptations to urban environments through its capacity to breed in such containers rather than natural water collections (Vezzani and Carbajo, 2008). This adaptation includes resistance of the Aedes eggs to desiccation and the feeding behaviour of females, which bite at multiple occasions during each gonadotrophic cycle (Regis et al., 2008). These characteristics, plus a wide distribution and high densities of breeding sites, constitute fundamental factors that influence the circulation and transmission of dengue and other related viruses in the region of northern Argentina (Rotela, 2012).

The incidence of dengue has grown dramatically in recent decades, with a concomitant increasing trend in dengue outbreaks in South America during the past few years (TDR/WHO, 2009). The largest previous notified dengue outbreak in Argentina occurred in 2009, reaching subtropical regions and affecting more than 25,900 people from localities, such as Buenos Aires and Córdoba, situated near the centre of the country (Seijo et al., 2009; Estallo et al., 2014). However, the largest percentage (>90\%) affected the northern provinces of Chaco, Catamarca and Salta (Argentinian Ministry of Health, 2009). During this outbreak, there were no dengue cases reported from Formosa Province (Argentinian Ministry of Health, 2009). Argentina is currently (2016) experiencing the strongest dengue outbreak in its history. Between weeks 1 and 15 of the epidemic, 56,802 cases compatible with dengue fever were confirmed by the national health system. So far, 28,008 cases are notified as indigenous and 2407 with a history of travelling to areas with local transmission and 1440 cases have been reported in Formosa Province (Argentinian Ministry of Health, 2016).

The existence of an endemic transmission cycle, introduction of 
cases by the movement of people across the border of countries with existing viral transmission and the absence of a vaccine (Avilés $e t$ al., 2003) have resulted in the development of dengue prevention mainly based on control of the vector. Effective serologic and viral surveillance programmes are often too expensive for the majority of developing countries affected by this disease, so they rely on entomologic surveillance to estimate the potential risk for virus transmission and disease (Bowman et al., 2016). The prevention programmes are therefore typically focused on the removal of Ae. aegypti breeding in order to eliminate vector larval stages (Getis et al., 2003), and they include elimination (source reduction) or treatment of larval habitats and insecticidal space spraying to reduce the density of adult mosquito population during periods of their occurrence (Getis et al., 2003). For this reason, a clear identification of vector hotspots in populated areas is an important tool for prevention programmes (Tran et al., 2004).

Multiple environmental factors, including biophysical and social ones, constitute a complex web that determines the spread of vectorborne diseases (Hales et al., 2002). Despite these complexities, various authors, Ostfeld et al. (2005) in particular, feel that an analysis of certain variables that have links to vectors and distribution of human cases can be a useful tool to generate space-time scenarios for dengue. In addition, spatial analysis of health events contributes to the early detection of areas involving disease transmission (Ostfeld et al., 2005). The Centers for Disease Control and Prevention (CDC) in the United States (USA) are clear about the fact that the detection of disease clusters allows the identification of non-random events that provides inferences about their epidemiological determinants (CDC, 1990). Surveillance tools, such as incidence maps, have been used to enhance public health operability before and during dengue outbreaks by providing visual aids for reaching a decision (Porcasi et al., 2012; Louis et al., 2014). Given that the risk generally increases with proximity to the infected host, the study of the factors that determine the spatial distribution of the host, the vector and the probability of interaction between them, are key points (Louis et al., 2014). In this context, spatial epidemiology, i.e. landscape epidemiology, can be defined as the study of the spatial variation of disease risk. This discipline, which tries to understand and explain the causes of spatial heterogeneity, is based on the idea that the spatial distribution of diseases is regulated by biological and physical variables (Ostfeld et al., 2005). Once the pattern is known, the future of the disease can be predicted (Pavlovsky, 1966).

Earth observation satellites constitute an interesting alternative to record environmental variables that influence diseases and are therefore useful for epidemiological studies. Remote sensing (RS) techniques allow the identification of key environmental factors such as characteristics of land cover, temperature, rainfall and humidity (Rotela et al., 2007; Polop et al., 2008). Since the beginning of RS technology, studies about vector-borne diseases have focused on identifying and mapping vector habitats (Hayes et al., 1985) as well as assessment of environmental factors related to vector biology (Rogers and Randolph, 1991, 1993; Kitron, 1998), thereby supporting the study of epidemiology (Linthicum et al., 1999; Murray, 2003). RS and spatial analysis have been utilised to identify map landscape elements that collectively define vector and human population dynamics, related to the risk of disease transmission (Wood et al., 1992; Glass et al., 1992). The development of increasingly sophisticated geographic information systems (GIS) has, together with RS, provided a new set of tools for public health professionals to monitor and respond to health challenges (Morrison et al., 1998; Carroll et al., 2014). These systems help pinpoint cases and exposures, identifying spatial trends and disease clusters, correlating different sets of spatial data, and testing statistical hypotheses. Nevertheless, risk maps are still not commonly used in public health contexts (Louis et al., 2014). Louis et al. (2014) showed the great diversity of predictors and modelling approaches needed to create dengue risk maps. However, this field is only in its beginning and still evolving. In addition, different studies propose that Ae. aegypti prevention and control actions should be based on results obtained from spatio-temporal data, both from the field and satellite imagery (Niño, 2011; De Melo et al., 2012; Estallo et al., 2015). The increase in the quality (accuracy) of field information used for the development of predictive maps should allow public health workers to identify areas of low or high risk for adequate disease control (Rotela et al., 2007; Halstead, 2008; Boyer et al., 2014). Despite the knowledge of Ae. aegypti biology and the use of monitoring tools for epidemiological surveillance and vector control services, the precise detection of sites with high-density vector breeding remains poorly understood. In fact, the direction and intensity of dispersion of vector breeding sites in urban areas over time is still unknown. The Argentinian government is currently working on an integrated dengue risk stratification system (Porcasi et al., 2012). Although its national scale module is well established, local scales need a deeper understanding. Several national academic teams are studying spatial vector dynamics in different cities and the kind of output that needs to be established to allow the use of predictive models in an operative context. Furthermore, a number of ideas have been proposed for the use of vector control strategies based on predictive maps generated from local environmental variables and field data. The purpose of this study is to analyse the temporal dynamics of the spatial distribution of $A e$. aegypti breeding sites in a city that has not instituted any vector control actions. Clorinda City, Formosa Province, Argentina is such a place, from where three years of dengue vector data are available.

\section{Materials and Methods}

\section{Study area}

The City of Clorinda $\left(25^{\circ} 17^{\prime} \mathrm{S}, 57^{\circ} 43^{\prime} \mathrm{W}\right)$ is located in the Province of Formosa, Argentina, $4 \mathrm{~km}$ from the Paraguayan border on the right bank of Pilcomayo River, $10 \mathrm{~km}$ before its confluence with Paraguay River (Figure 1). This city lies in the humid Chaco region and presents

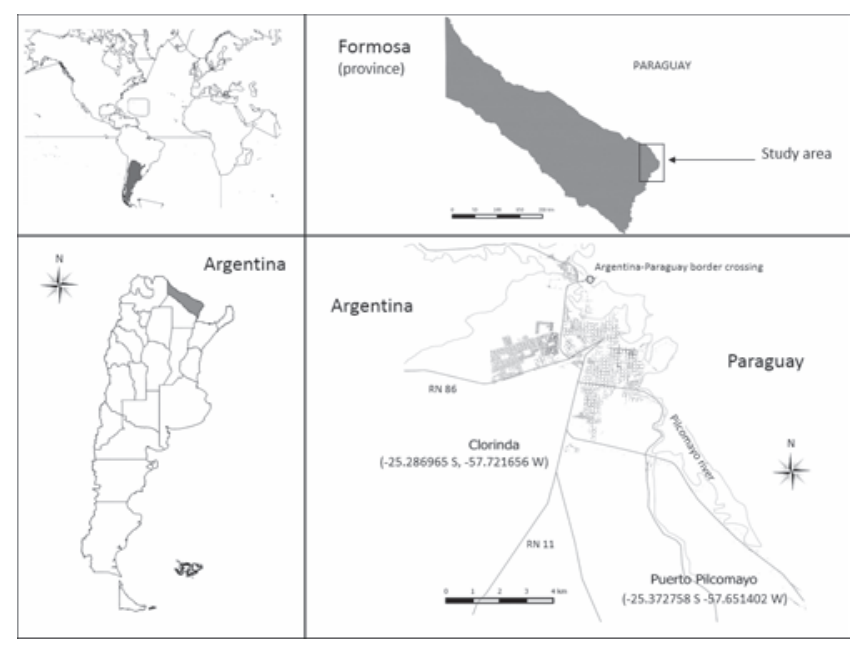

Figure 1. Geographic area of Aedes aegypti larval sampling in Clorinda and Puerto Pilcomayo (Formosa Province, Argentina), 2012-2014. 
a subtropical climate without a dry season. Annual median temperature is about $23^{\circ} \mathrm{C}$ and the mean annual precipitation $1300 \mathrm{~mm}$, due to a rainy season stretching from October to May (Masuh et al., 2003; Gurtler et al., 2009). The urban area is comprised by 980 blocks of buildings and the entomologic surveillance area of this study included 16,511 houses belonging to these blocks. Each house was georeferenced by the use of a handheld GPS equipment (Garmín ${ }^{\mathrm{TM}}$ eTrex Legend ${ }^{\circledR} \mathrm{HCx}$; Garmin, Olathe, KS, USA). Clorinda City is characterised by its ethnic cultural diversity, due to the presence of several indigenous groups and migrant populations from the bordering countries, above all from Paraguay. This feature produces an important effect on the cultural, social and economic profile of these communities (Masuh et al., 2003).

\section{Entomologic data}

From October 2011 to October 2014, the presence and abundance of Ae. aegypti breeding sites in Clorinda City were registered and in each time $20 \%$ of the total number of houses was selected by random distribution sampling for monitoring. During this period, a total of 12 entomological surveys were performed (Table 1) and the results grouped by year in order to conduct space-time analysis. In all households from a selected block that had agreed to participate, the water containers were grouped into different categories (tires, tanks, drums, barrels vases, etc.) and the total number of containers recorded, including information on which had water and which had larvae. All larvae were collected and moved to the Entomologic Laboratory of Fundación Mundo Sano in Clorinda City for taxonomic determination using a specific morphological key (Rossi and Almirón, 2004). Fundación Mundo Sano is a scientific, non-governmental foundation in Argentina engaged in control and prevention of communicable diseases. Houses found to have at least one container with one or more Ae. aegypti larvae or pupae were considered a positive site. For each year, the entomological indices at the housing unit level were calculated using stegomyia indices: house index $(\mathrm{HI})=$ the number of positive homes/number of houses inspected) $\times 100$; and Breteau index $(\mathrm{BI})=$ the total number of breeding sites/number of houses inspected) $\times 100$ (Ibañez-Bernal and GomezDantes, 1995).

The free Quantum GIS Desktop, version 2.6.1. Brighton (QGIS) (http:/www.qgis.org/) software was used to build the point vector layers (.shp) locating samples points, recording sites of mosquito presence, collecting abundance data for each survey and grouping them per year. Based on those layers, the QGIS heatmap tool (estimating the density of positive sites) was used to create hotspot maps for each year. Moreover, cluster analysis methodology was applied to identify spatial clusters (Kulldorf and Hjalmars, 1999). Sites with presence of larval stages were indicated as positive cases (1) and those without were indicated as negative (0). The analysis consisted of a spatial scan through the superposition of exploratory circles over sites with a record of larval presence. Each circle was seen as a possible cluster and, taking into consideration the number of events inside and outside an expected number of events, the probability was calculated. The circle that presented the maximum probability and excess in the number of events observed $v s$ expected, was defined as the most probable cluster (Kulldorf and Hjalmars, 1999). Based on the results of this exploratory analysis and the knowledge of the roads and demographic stratus of the city, we defined five particular zones. The temporal development, based on the mean numbers of positive breeding sites for each zone for each of the three sampling years, was analysed in order to evaluate whether the zones in the urban geography presented different responses to the environmental annual oscillation.

\section{Land cover}

Images from the satellite SPOT 5 (http://www.geoimage.com.au/ satellite/spot-5) were used to characterise environmental coverage types in Clorinda City. This commercial imaging satellite system provides a $10-\mathrm{m}$ multispectral resolution image in its SPOT 5 product $\mathrm{J}$ with four spectral bands: green $(0.50-0.59 \mu \mathrm{m})$, red $(0.61-0.68 \mu \mathrm{m})$, near infrared $(0.78-0.89 \mu \mathrm{m})$, and middle infrared $(1.58-1.75 \mu \mathrm{m})$. All images used were supplied by National Commission on Space Activities (CONAE) in Argentina (http//www.conae.gov.ar/index.php/). The SPOT image from April 29, 2013 (approximately in the middle of sampling period) was used to generate a land cover classification and

Table 1. Temporal sequence of entomologic sampling surveys for Aedes aegypti breeding sites in Clorinda City, 2012-2014.

\begin{tabular}{lcc}
$\begin{array}{c}\text { Sampling number } \\
\text { date (day/month/year) }\end{array}$ & $\begin{array}{c}\text { Start } \\
\text { End } \\
\text { date (day/month/year) }\end{array}$ \\
17 & $17 / 10 / 2011$ & $16 / 02 / 2012$ \\
18 & $16 / 02 / 2012$ & $04 / 06 / 2012$ \\
\hline 19 & $05 / 06 / 2012$ & $31 / 08 / 2012$ \\
20 & $23 / 08 / 2012$ & $07 / 11 / 2012$ \\
\hline 21 & $07 / 11 / 2012$ & $04 / 03 / 2013$ \\
22 & $04 / 03 / 2013$ & $27 / 05 / 2013$ \\
\hline 23 & $23 / 05 / 2013$ & $13 / 08 / 2013$ \\
24 & $13 / 08 / 2013$ & $07 / 10 / 2013$ \\
\hline 25 & $07 / 10 / 2013$ & $28 / 11 / 2013$ \\
26 & $05 / 12 / 2013$ & $06 / 05 / 2014$ \\
\hline 27 & $07 / 05 / 2014$ & $05 / 08 / 2014$ \\
28 & $06 / 08 / 2014$ & $27 / 10 / 2014$ \\
\hline
\end{tabular}

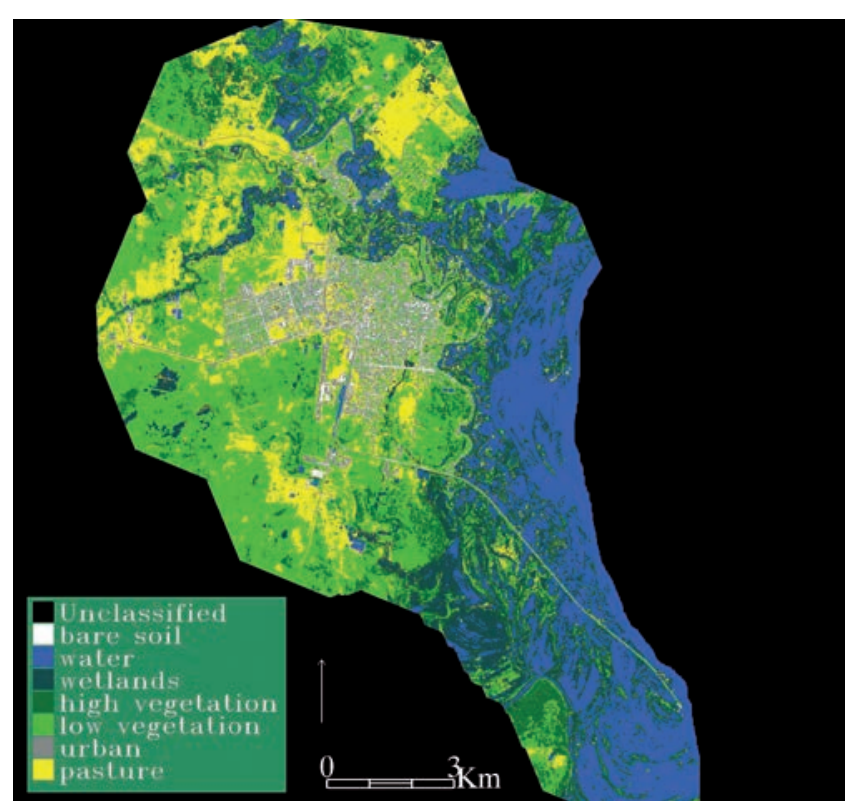

Figure 2. SPOT 5 satellite image of the Clorinda Region with seven different classes of landscape variables. Unsupervised classification (K-means). 
macro-environmental products of the study area (Figure 2). Unsupervised classification (K-means) was performed to classify the study area image following the methodology indicated by Rotela $\mathrm{et} \mathrm{al}$. (2010). Seven land cover classes were defined: bare soil; superficial water or water; wetlands; low vegetation (grass); high vegetation (trees); urban buildings; and pasture/crops. Through the use of Google Earth, a set of 40 control points (ground truth) was created for each environmental cover to corroborate the accuracy of the classification. The confusion matrix used with validation control points showed an overall accuracy of $77.6 \%$ and a Kappa coefficient of 0.74 . Some classes (water, pasture/crops, low and high vegetation, wetlands) reached values above $80 \%$ accuracy, while other (bare soil and urban buildings) presented 50 and 76\% accuracy, respectively. QGIS, version 2.6.1 and ENVI, version 4.8 (Exelis Visual Information Solutions, Boulder, C0, USA) software were used to create classification images and vectors to assess accuracy level of classifications.

Based on the land cover classes created, two different types of macro-environmental variables were generated from each class and expressed as i) Buffer Image (Figure 3) here called Bare soil distribution, Low vegetation distribution, etc.; and ii) percentage of each land cover class (Figure 4) by applying the methodology described by Rotela et al. (2010). The window size for the generation of the percentage map was $31 \times 31$ pixels, attributing the average value of the window pixels to the central pixel. To generate the new land cover classes (distribution and percentage), we considered a 300-m diameter buffer zone, based on available evidence of the Ae. aegypti flying range (Trpis and Hausermann, 1986; Ordoñez et al., 1997) that was accepted as the average habitat of the species. All these analyses were performed with the ENVI 4.8 geospatial software. In addition, a hotspot buffer layer shapefile was created as a distance map to critical points (cemetery and garbage dump). Finally, the normalised burn ratio thermal (NBRT) layer was included as proxy for the annual land surface temperature according to Espinosa et al. (2016). This index includes near infrared, short wave infrared (SWIR) and thermal infrared Landsat bands (http://andsat.gsfc.nasa.gov/). These composites are made from Level L1T orthorectified scenes, using the computed top-of-atmosphere reflectance (Holden et al., 2005) and can be obtained from several Earth data repositories, for example in Google Earth Engine.

Subsequently, information provided by the Argentinean National Institute of Statistics and Censuses - INDEC, processed with Redatam + Sp (http://www.indec.gov.ar) was used to generate a layer that included demographic information related to the availability of drinking water (public network) (Figure 4). This layer reflects the lack of this public service as an indicator of the use of outdoor water storage containers that could function as aegypti breeding sites. The INDEC data were transformed, by the QGIS software, into a vector layer including percentage values of this service.

\section{Modelling vector-presence probability}

In order to assess the contribution of each of the selected variables in the prediction of suitable Ae. aegypti breeding sites in the City of Clorinda, the maximum entropy (MaxEnt) program, version 3.3.3a software (http:/www.cs.princeton.edu/ schapire/maxent/) was run to generate vector presence probability maps based on the macro-environmental layers created (Peterson, 2001, 2003; Elith et al., 2006; Rotela et al., 2007). It was run with 1000 repetitions using $75 \%$ of vector presence points for model training and $25 \%$ for validation. In general, the MaxEnt algorithm detects non-random relationships between two datasets: i) georeferenced records of species presence, and ii) a set of raster land cover types representing the environmental and demographic variables considered relevant to determine Ae. aegypti distribution (Phillips et al., 2006). The environmental dataset used consisted of 23 raster format variables of 10-m spatial resolution (Appendix 1).

The ecological modelling calculates the probability of presence of
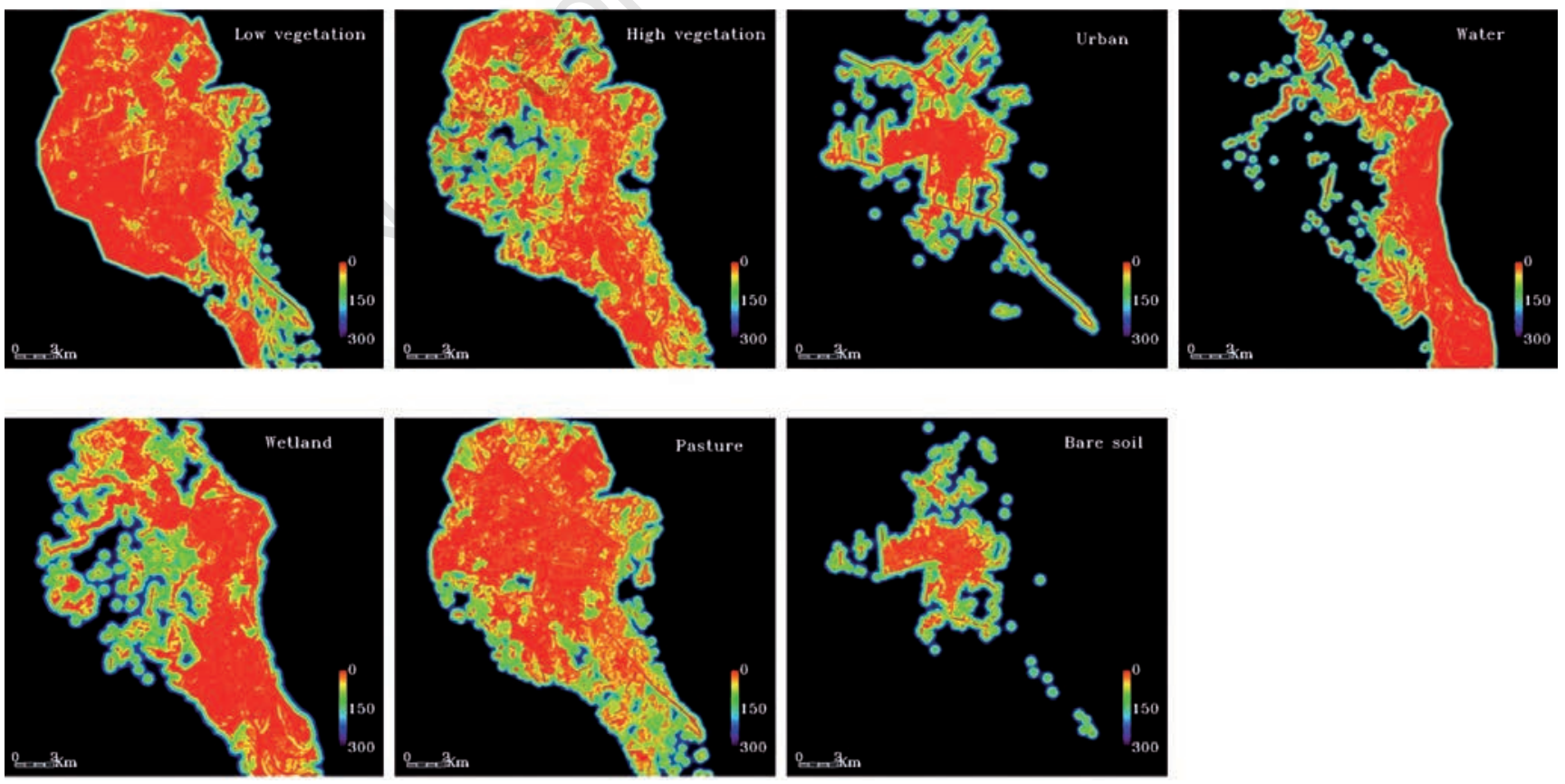

Figure 3. Distance maps centred on Clorinda City. The various landscape variables are as indicated in the legend (300 $\mathrm{m}$ buffer). 
vector breeding sites based on environmental and demographic variables and the recorded presence of vector breeding sites for training and testing. All Ae. aegypti breeding sites from the 2014 survey in Clorinda were used. In order to do that, a product compiling all variable values was generated. Thus, each pixel of the study area represents different landscape values (from the set of variables shown in Appendix 1) and an associated value indicating the probability of the presence of a breeding site. For this analysis, two basic premises were taken into account, one related to the presence of sites where the Aedes species successfully grows, and another referred to the selected environmental variables that adequately represent the ecological requirements of this species. Each presence site was indicated by a pair of geographic coordinates (WGS84 Datum) and represented places where Ae. aegypti breeding sites were found during the sampling period.

\section{Results}

From 2012 to 2014, 12 samplings recording Ae. aegypti breeding sites in about 2500 houses during the entire sampling period were performed and recorded including the two stegomyia indices ( $\mathrm{HI}$ and $\mathrm{BI}$ ) obtained for each year (Table 2). The number and distribution of $A e$. aegypti breeding sites found in Clorinda City for each sampling year are presented in Table 2 and Figure 5.

Figure 6 shows the result of hotspot analysis per sampling year based on entomological data. A broad distribution with evidence of a small high-density zone north of Clorinda City and a high-density region in the centre can be seen. The southwest to northeast cluster line remained similar during the three years.

The infestation pattern observed each year led us to define the five regions presented in Figure 7A. The annual density of breeding sites for each year and each zone, extracted from Figure 6 data, are presented in Figure 7B. Centre-west and southeast regions present more similar abundance levels each year to the total city pattern (A2013>A2012>A2014), while the centre-east and northern regions show different inter-annual variability (A2012>A2013>A2014) (Figure 7B). Although a general temporal pattern can be recognised in the previous analysis, we can see that some city zones have a dynamic of their own, a remarkable finding considering the small size of Clorinda City that does not have any systematic control activities.

MaxEnt software results show that the spatial pattern of our vector data is principally related to the set of indicators presented in Table 3 , which underlines the importance of the percentage of the contribution and permutation of the model's principal variables. The predictive map obtained by the model was assessed with the measurement of the area

Table 2. Entomologic samplings performed in Clorinda City showing the House and Breteau indices obtained.

\begin{tabular}{lccccccc}
\hline Year & Samplings (n) & Houses visited (n) & Positive houses (n) & Breeding sites (n) & HII (\%) & BI (\%) \\
\hline 2012 & 4 & 7468 & 1027 & 1135 & 13.75 & 15.19 \\
2013 & 5 & 10,224 & 881 & 1392 & 8.61 & 13.61 \\
\hline 2014 & 3 & 7030 & 612 & 981 & 8.7 & 13.95 \\
\hline
\end{tabular}

HI, house index; BI, Breteau index
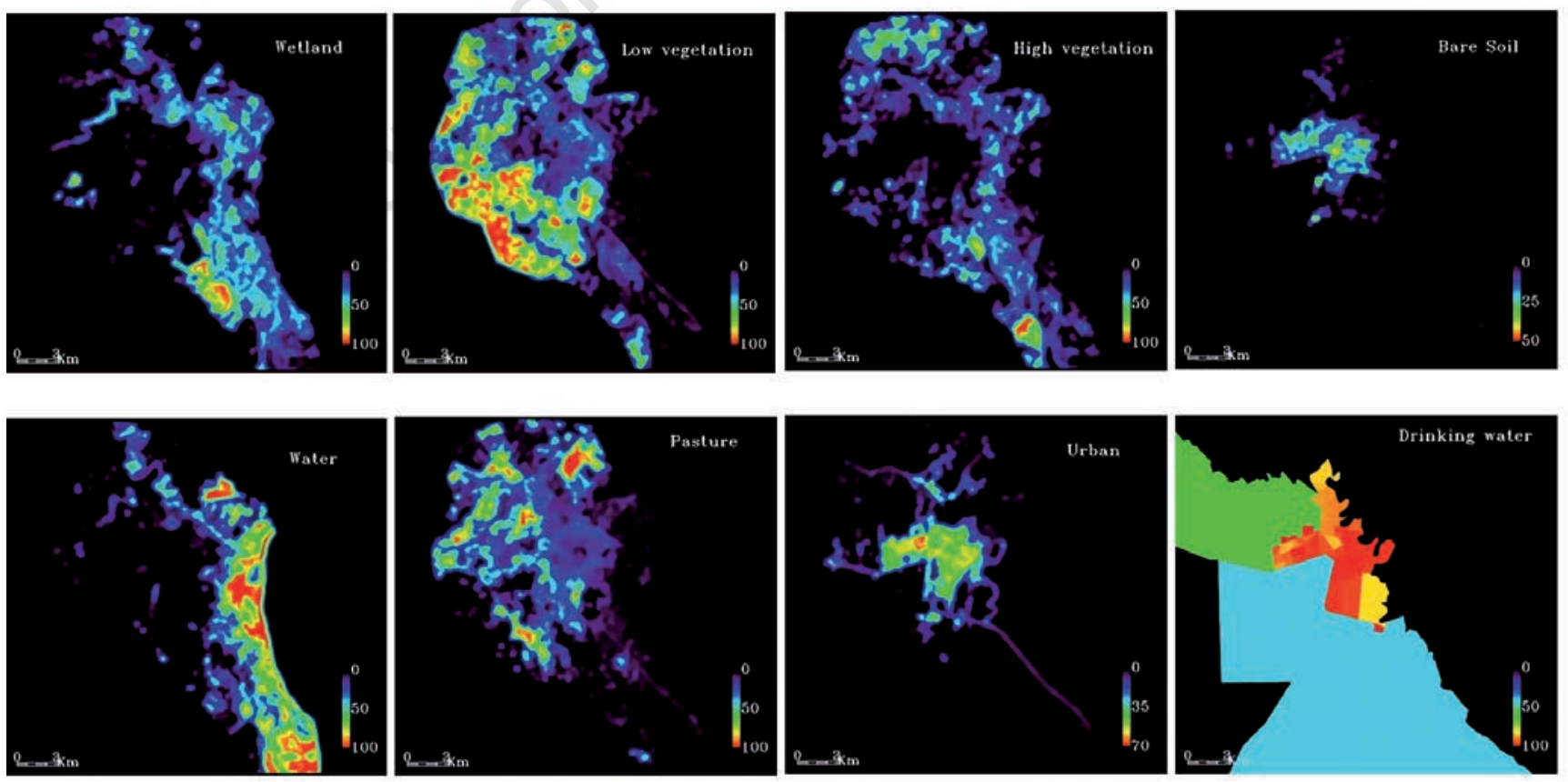

Figure 4. Variable class percentage maps at Clorinda City. The various landscape variables are as indicated in the legend (300 $\mathrm{m}$ buffer). 
under the curve using receiver operating characteristic analysis, which indicates the global accuracy of the test (Deleo, 1993). In this case, the analysis scored 0.965 with a standard deviation of 0.003 , which means that the predictive ability of our model generated for the 2014 dataset must be classified as very good according to the scheme mentioned by Parolo et al. (2008). The model predicted that the best environmental variables explaining $85.8 \%$ of the distribution of the breeding sites were water containers (48.2\%), urban building distribution (33.2\%) and urban building percentage (4.4\%) (Table 3). The probability map for Ae. aegypti breeding sites generated by this ecological niche model is presented in Figure 8.

\section{Discussion}

This study presents relevant results on how Ae. aegypti breeding sites are distributed during three years of spatial pattern dynamics in a small town in the North of Argentina. The focus is based on the different results that can be found between typical analysis based on only one year of sampling data and the temporal evolution of patterns when no control intervention is performed. Relevant results about $A e$. aegypti breeding site distribution in the study area are presented taking into account dynamic spatial patterns that estimate the evolution of vector populations in an environment free of vector control. Maps showing high-density of Ae. aegypti breeding sites indicate a greater proportion and persistence (in time) of four principal cluster areas. The increase in density of positive breeding sites from 2012 to 2014 was observed in association with the increase in the stegomyia indices (both $\mathrm{HI}$ and BI). This behaviour is in agreement with observations obtained from other areas under no vector control (Rotela, 2012) in Puerto Iguazú City, but differs from the results obtained by Espinosa et al. (2016) in the City of Tartagal, where there was a significant reduction in breeding site density related to vector control activities.

Clorinda's high-density clusters are characterised by a deficit in the supply of potable water, especially during the summer months (Garelli et al., 2011) promoting the accumulation of a diverse array of containers for water storage near the houses. Generally, most of these containers are uncovered, thereby constituting excellent breeding sites for $A e$. aegypti. A previous study conducted in Clorinda City concluded that this practice is due to a cultural pattern adopted to face the lack of access to water that constitutes a complex set of factors influencing the abundance of breeding sites and mosquito population dynamics (Garelli $e t$ al., 2011). In addition, the lack of a relationship between precipitation
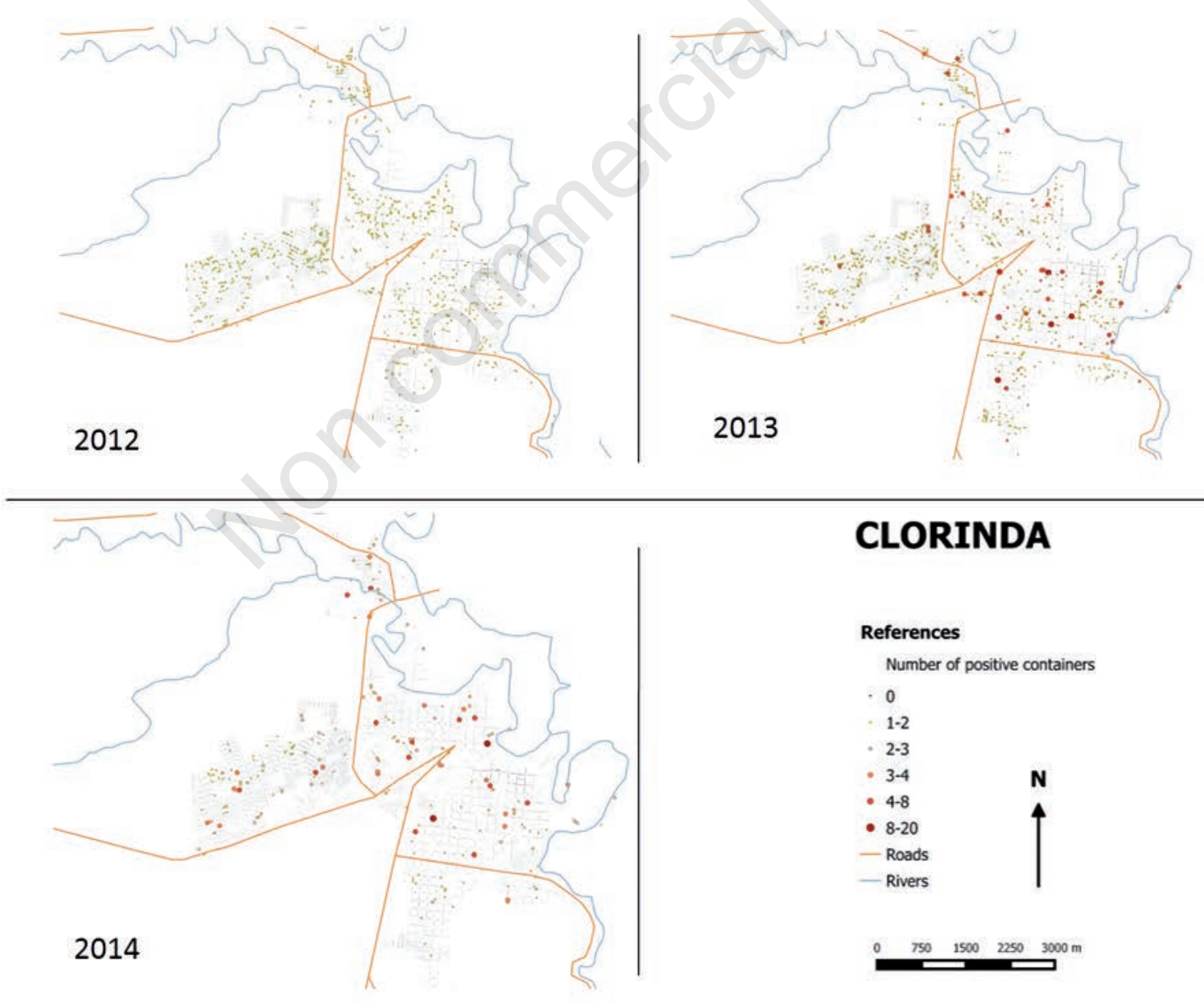

\section{CLORINDA}

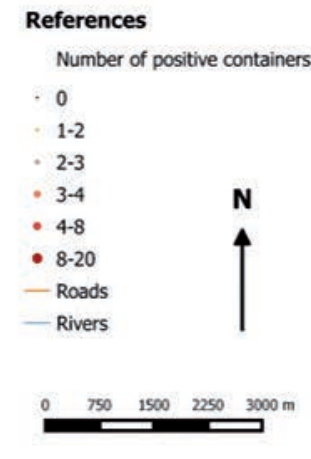

Figure 5. Distribution of total number of surveyed houses in Clorinda City expressing the number of positive containers found for Aedes aegypti larvae in each sampling year. 
and number of breeding sites found in Puerto Iguazú City (Rotela, 2012) highlights the importance of the use of water storage containers and the increase of mosquito breeding sites independently of this weather variable. Therefore, a chain is created resulting in an increase in vector density leading to an increase in vector-human contact that finally produces a higher viral transmission rates among the human population during epidemic events (Siqueira-Junior et al., 2008; Eisen and Lozano-Fuentes, 2009). This converts the detection of vector density changes into an important factor in the epidemiology of the disease (Niño, 2011).

Table 3. Relative contribution of the environmental variables in the maximum entropy model.

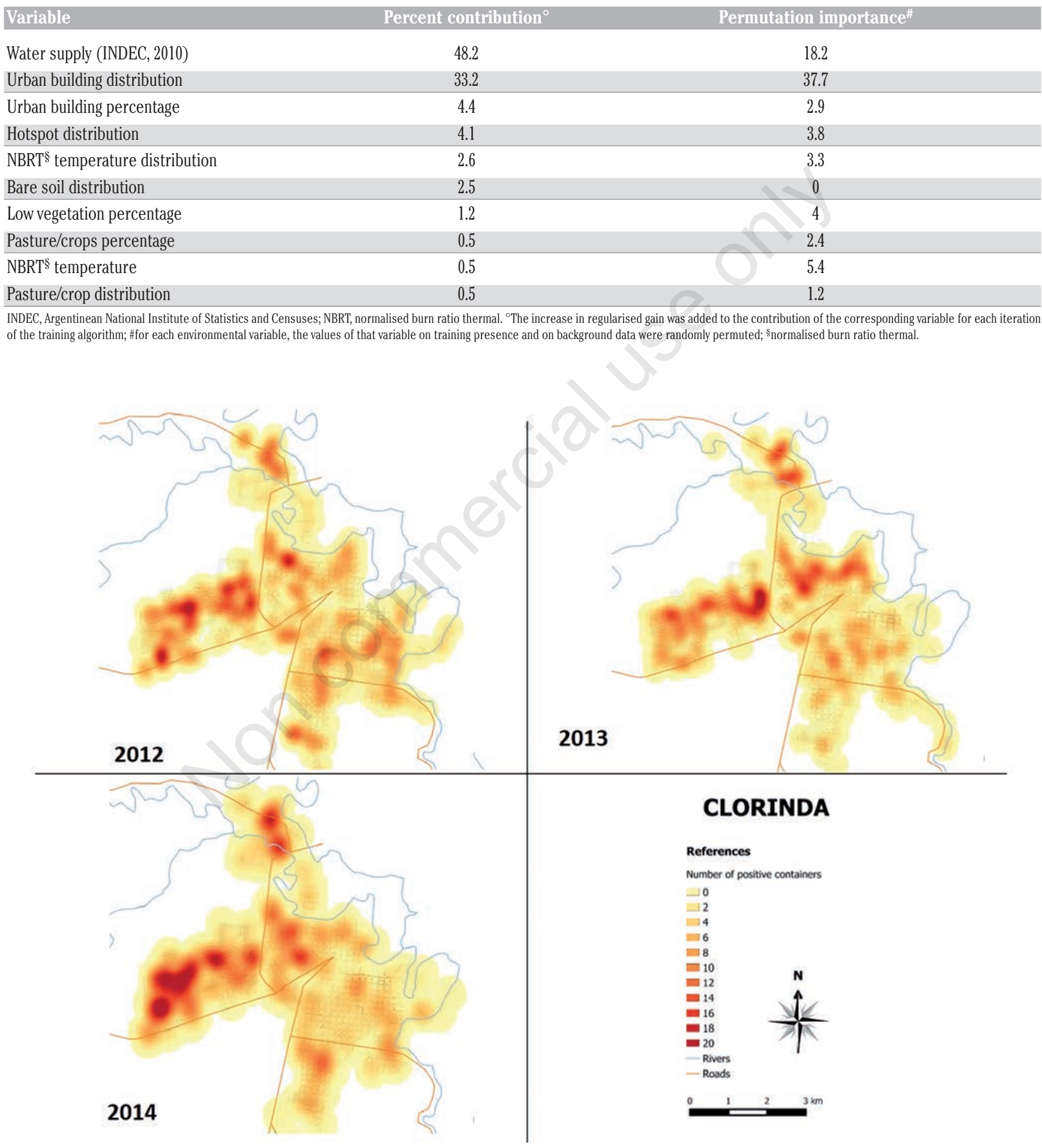

Figure 6. Annual density in the summer-autumn period of Aedes aegypti breeding sites in Clorinda City. 
The presence of high-density breeding sites, which remained stable during all the study period, was found to be strongly related to suitable areas predicted by the ecological niche model based on environmental and socioeconomic conditions. Indeed, the spatial dataset of vectors and environmental variables used to generate the probability map allowed predicting over $95 \%$ of the positive breeding sites. The variables found to be most contributing to the breeding site distribution are consistent with results reported by Porcasi et al. (2012) and Rotela et al. (2012) for other cities in northern Argentina. However, the findings are in contrast to findings by Vezzani et al. (2005) for microhabitat suitability in the southern latitudes, e.g. Buenos Aires, a fact that reinforces the results obtained here taking into account that one of the key aspects to reduce the abundance of the vector involves the identification of Ae. aegypti breeding sites (Aviles et al., 2003).

Considering the complexity of variables that affect the distribution of anthropophilic vectors such as Ae. aegypti, spatial analysis tools and GIS applied in the current study allowed the generation of a map showing positive breeding sites as well as the determination of the more significant variables supporting this development. The predictive power with respect to the presence of Ae. aegypti breeding sites produced by the model generated for Clorinda City is in accordance with Parolo et $a l$. (2008). The vector presence probability maps, with values exceeding $85 \%$, clearly showed that the increased risk was associated with three principal clustered sectors in the city, strongly related with hotspots (one located in the North, one in the West and one in the East of the city). The convergence of Heatmap clusters and the three sectors identified as the most likely areas with vector presence (Ae. aegypti breeding sites) in contrast to the sectors with lower probabilities (0$30 \%$ ) shows the suitability of our model in environments where vector control has not been implemented.

In Clorinda City, and in accordance with 0stfeld et al. (2005), WHO (2014) and Troyo et al. (2009), RS information has been used to determine the type of land cover that favours the presence of breeding sites and survival of Ae. aegypti. The performance obtained by the MaxEnt model could allow the establishment of the proposed methodology, to generate continuous breeding site maps, like a valid one when used with contemporary field data. The great quantity of field data collected and analysed in Clorinda City allowed us to evaluate the model's predictive capacity, confirming the necessity to use large time series of local data (entomological and environmental) for the construction of predictive models, which allows the application of more efficient control actions (Louis et al., 2014). In addition, our results support previous predictive models developed by Porcasi et al. (2012), Rotela et al. (2010), and Rotela (2012) offering tools to improve health system responses with respect to vector and virus transmission control, which have relevance not only for dengue but also other vector-dependent viral diseases.

\section{Conclusions}

As usual, the results do not completely agree with the results expected by the study team. Our hypothesis was that in a small city without systematic control activities, the breeding site pattern $\mathrm{NB}(x, y, t)$ should have a quasi-uniform time evolution for the whole city. This means that $\mathrm{NB}(x, y, t)=\mathrm{f}(x, y)^{*} \mathrm{~g}(t)$, i.e. the relative spatial pattern, should basically be the same modulated only by the temporal function (the city as a whole is expected to respond similarly to the annual climatic variability). In this case, the spatial map obtained for a specific year, could be used for others years, because the relative values are temporally invari- ant. Inversely, however, it is clear that our results (Figure 7B) show a differential temporal behaviour for each intra-city zone. For example, from 2012 to 2013, in the southern and southeastern areas, there is an increase in the mean number of breeding sites, meanwhile in the North and Centre-East, the risk decreased from 2012 to 2013. This means that our hypothesis is clearly rejected. Thus, more studies are needed to understand this intra-city dynamic and its regulatory microand macro-environmental variables.

\section{A}

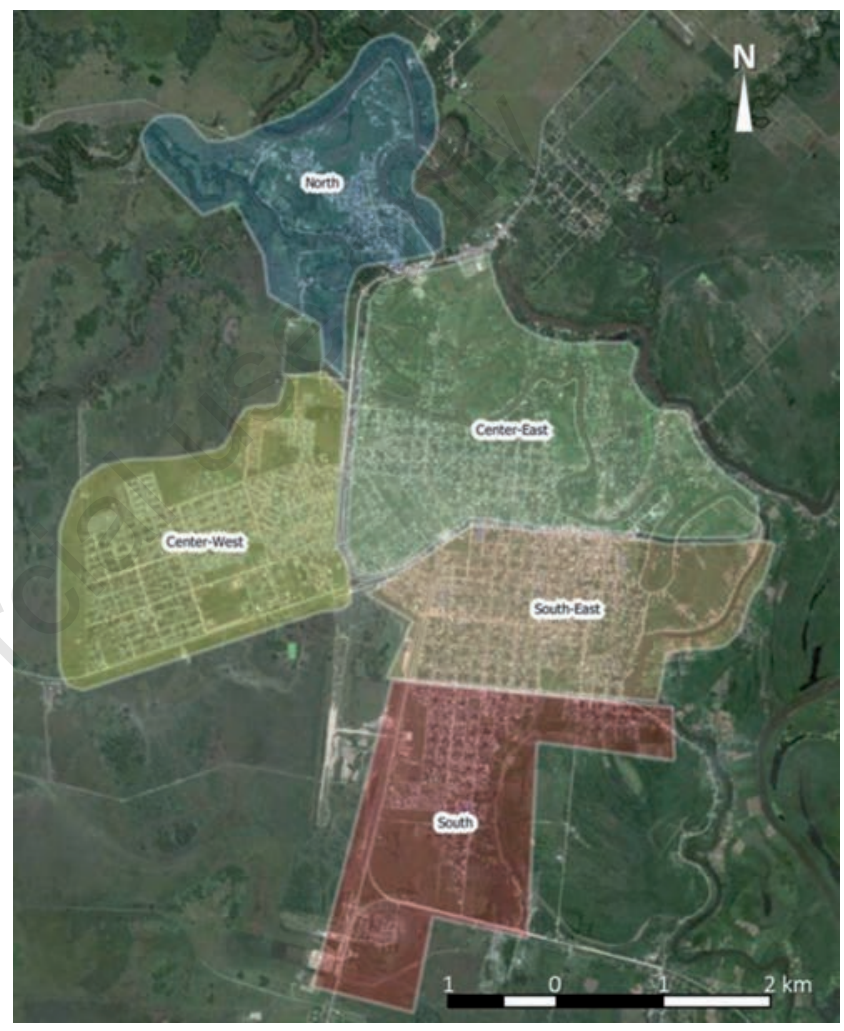

B

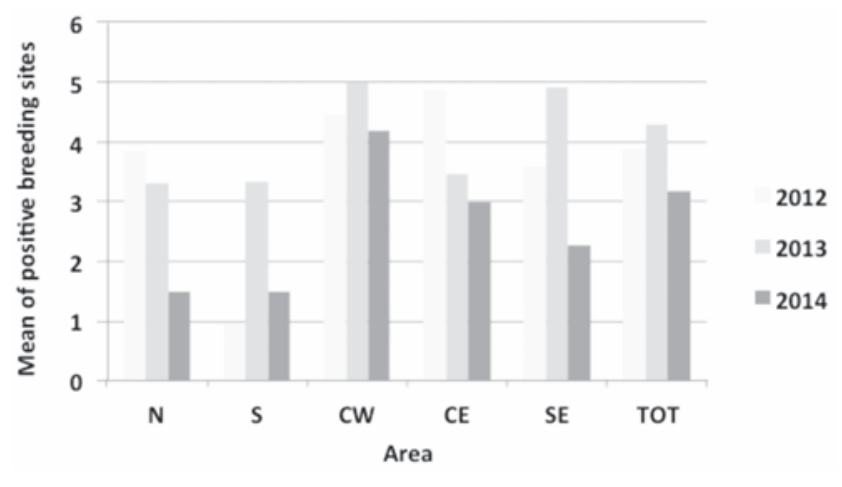

Figure 7. A) Regions in Clorinda City defined for particular temporal analysis; B) mean of positive breeding sites per house for areas showed in A) for the three sampling years. N, North; S, South; CW, Centre-West; CE, Centre-East; SE, Southeast; TOT, total annual. 


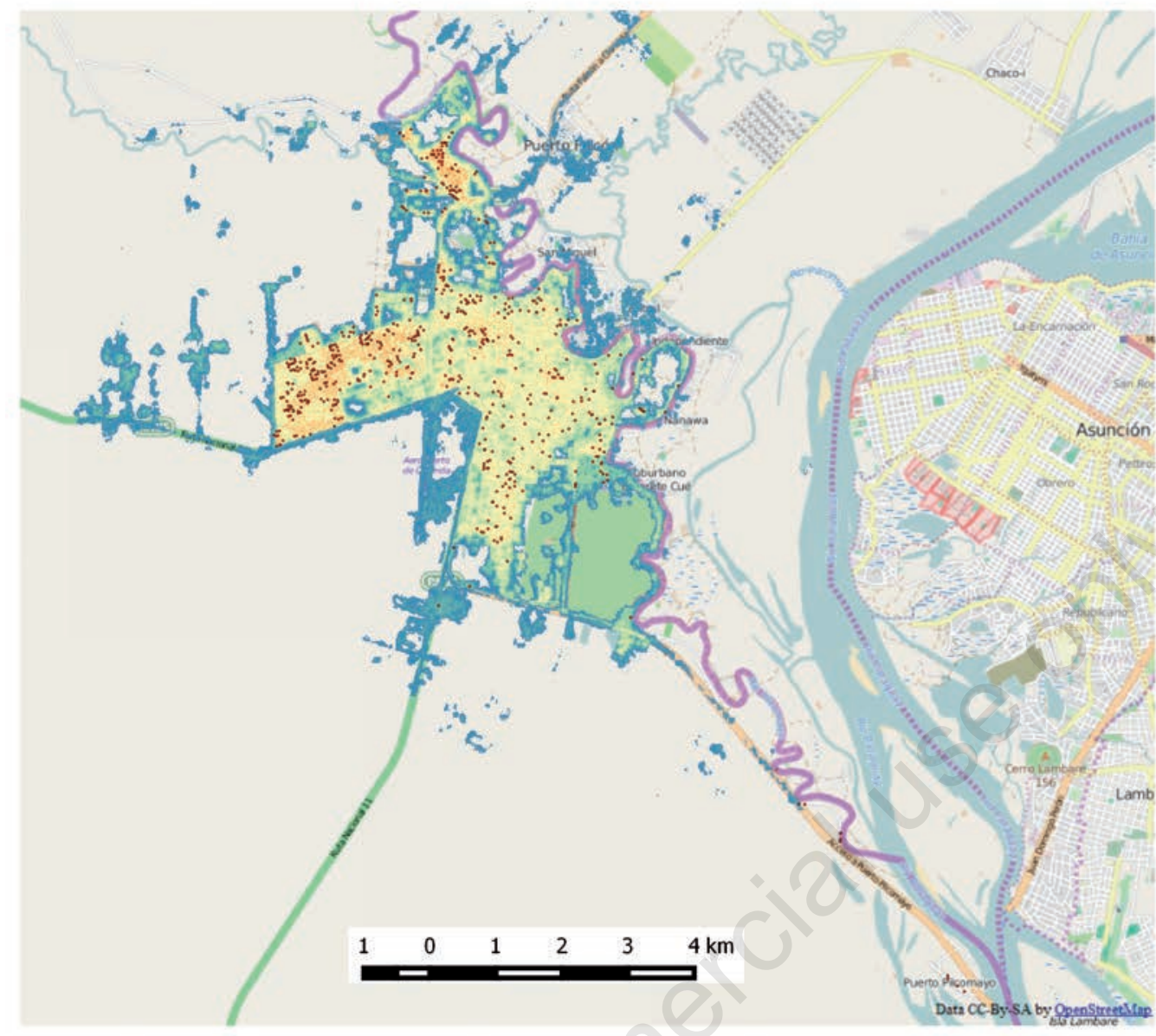

Maxent Bil

- MuestreosPositivos2014 OpenStreetMap

Probabilidad Maxent

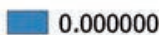

0.052632

0.105263

0.157895

0.210526

0.263158

0.315789

0.368421

0.421053

0.473684

0.526316

0.578947

0.631579

0.684211

0.736842

0.789474

0.842105

0.894737

0.947368

1.000000

Figure 8. Probability map for Aedes aegypti breeding sites generated by the maximum entropy model (MaxEnt). Blue areas represent a null risk for developing breeding sites, while red areas are the most suitable habitats for vector breeding sites.

\section{References}

Argentinian Ministry of Health, 2009. [Boletín epidemiológico nacional]. [Book in Spanish]. Argentinian Ministry of Health, Buenos Aires, Argentina. Available from: http://www.msal.gob.ar/saladesituacion/boletines_epidemiologia/pdfs/BEPANUAL_2009.pdf

Argentinian Ministry of Health, 2016. [Boletín epidemiológico nacional]. [Book in Spanish]. Argentinian Ministry of Health, Buenos Aires, Argentina. Available from: http:/www.msal.gob.ar/images/ stories/boletines/Boletin-Integrado-De-Vigilancia-N305-SE15.pdf

Aviles G, Paz MV, Rangeon G, Ranaivoarisoa MY, Verzeri N, Roginski S, Baroni P, Enría D, 2003. Laboratory surveillance of dengue in Argentina, 1995-2001. Emerg Infect Dis 9:738-42.

Boyer S, Foray C, Dehecq JS, 2014. Spatial and temporal heterogeneities of Aedes albopictus density in La Reunion Island: rise and weakness of entomological indices. PLoS ONE 9:e91170.

Bowman LR, Donegan S, McCall PJ, 2016. Is dengue vector control deficient in effectiveness or evidence? Systematic review and metaanalysis. PLoS Negl Trop Dis 10:e004551.

Carroll LN, Au AP, Detwiler LT, Fu TC, Painter IS, Abernethy NF, 2014. Visualization and analytics tools for infectious disease epidemiolo- gy: a systematic review. J Biomed Inform 51:287-98.

CDC, 1990. Guidelines for investigating clusters of health events. Centers for Disease Control and Prevention, Atlanta, GA, USA. Available from: http:/www.cdc.gov/mmwr/preview/mmwrhtml/00001797.htm

Deleo JM, 1993. Receiver operating characteristic laboratory (ROCLAB): software for developing decision strategies that account for uncertainty. In: Proceedings of the Second International Symposium on Uncertainty Modelling and Analysis. IEEE Com-puter Society Press, College Park, MD, USA, pp 318-25.

De Melo DP, Scherrer LR, Eiras AE, 2012. Dengue fever occurrence and vector detection by larval survey, ovitrap and MosquiTRAP: a spacetime clusters analysis. PLoS ONE 7:e42125.

Eisen L, Lozano-Fuentes S, 2009. Use of mapping and spatial and space-time modeling approaches in operational control of Aedes aegypti and dengue. PLoS Negl Trop Dis 3:e411.

Elith J, Graham CH, Zimmermann NE, 2006. Novel methods improve prediction of species' distribution from occurrence data. Ecogeography 29:129-51.

Espinosa M, Weinberg D, Rotela CH, Polop F, Abril M, Scavuzzo CM, 2016. Temporal dynamics and spatial patterns of Aedes aegypti breeding sites, in the context of a dengue control program in 
Tartagal (Salta province, Argentina). PLoS One 10:e0004621.

Estallo EL, Carbajo AE, Grech MG, Frias-Cespedes M, Lopez L, Lanfri MA, Ludueña-Almeida FF, Almirón WR, 2014. Spatio-temporal dynamics of dengue 2009 outbreak in Cordoba City, Argentina. Acta Trop 136:129-36.

Estallo EL, Luduena-Almeida FF, Introini MV, Zaidenberg M, Almiron WR, 2015. Weather variability associated with Aedes (stegomyia) aegypti (dengue vector) oviposition dynamics in Northwestern Argentina. PLoS ONE 10:1-11.

Garelli FM, Espinosa M0, Weinberg D, Trinelli MA, Gurtler RE, 2011. Water use practices limit the effectiveness of a temephos-based Aedes aegypti larval control program in Northern Argentina. PLoS Negl Trop Dis 5:1-9.

Getis A, Morrison AC, Gray K, Scott TW, 2003. Characteristics of the spatial pattern of the dengue vector, Aedes aegypti, in Iquitos, Peru. Am J Trop Med Hyg 69:494-505.

Glass GE, Morgan III, Johnson JM, Noy DT, Israel PM, Schwartz E. Infectious disease epidemiology and GIS: a case study of lyme disease. Geo Info Systems 1992;2:65-9.

Gubler DJ, 1997. Dengue and dengue hemorrhagic fever: its history and resurgence as a global public health problem. In: Gubler DJ, Kuno $\mathrm{G}$, eds. Dengue and dengue hemorrhagic fever. CAB International, New York, NY, USA, pp 1-22.

Gürtler RE, Garelli FM, Coto HD, 2009. Effects of a five-year citywide intervention program to control Aedes aegypti and prevent dengue outbreaks in Northern Argentina. PLoS Negl Trop Dis 3:e427.

Hales S, de Wet N, Maindonald J, Woodward A, 2002. Potential effect of population and climate changes on global distribution of dengue fever: an empirical model. Lancet 360:830-4.

Halstead SB, 2008. Dengue virus-mosquito interactions. Annu Rev Entomol 53:273-91.

Hayes R0, Maxwell EL, Mitchell CJ, Woodzick TL, 1985. Detection, identification, and classification of mosquito larval habitats using remote sensing scanners in earth-orbiting satellites. B World Health Organ 63:361-74.

Holden ZA, Smith AMS, Morgan P, Rollins MG, Gesslera PE, 2005. Evaluation of novel thermally enhanced spectral indices for mapping fire perimeters and comparisons with fire atlas data. Int $\mathbf{J}$ Remote Sens 26:4801-8.

Ibañez-Bernal S, Gomez-Dantes H, 1995. Vectors of dengue in Mexico: a critical review. Salud Publica Mexico 37:53-63.

Kitron U, 1998. Landscape ecology and epidemiology of vector-borne diseases: tools for spatial analysis. J Med Entomol 35:435-45.

Kulldorff M, Hjalmars U, 1999. The Knox method and other tests for space-time interaction. Biometrics 55:544-52.

Linthcum KJ, Anyamba A, Tucker CJ, Kelley PW, Myers MF, Peters CJ, 1999. Climate and satellite indicators to forecast Rift Valley fever epidemics in Kenya. Science 285:397-400.

Louis VR, Phalkey R, Horstick 0, Ratanawong P, Wilder-Smith A, Tozan Y, Dambach P, 2014. Modeling tools for dengue risk mapping: a systematic review. Int J Health Geogr 13:50.

Masuh H, Coto H, Licastro S, Zerba E, 2003. [Control de Aedes aegypti en Clorinda: un modelo para áreas urbanas]. [Article in Spanish]. Entomol Vect 10:485-94.

Morrison AC, Getis A, Santiago M, Rigau-Perez JG, Reiter P, 1998. Exploratory space-time analysis of reported dengue cases during an outbreak in Florida, Puerto Rico, 1991-1992. Am J Trop Med Hyg $58: 287-98$

Murray J, 2003. Spatial models and biomedical applications. SpringerVerlag, Berlin, Germany.

Niño L, 2011. Spatial interpolation of Aedes aegypti larvae abundance for locating infestation foci. Rev Panam Salud Publica 29:416-22.

Ordoñez JG, Fernandez Salas I, Flores-Leal A, 1997. Monitoring dispersal of marked Aedes aegypti females under field conditions using sticky ovitraps in Monterrey, northeastern Mexico. J Am Mosquito Contr 13:121.

Ostfeld RS, Glass GE, Keesing F, 2005. Spatial epidemiology: an emerging (or re-emerging) discipline. Trends Ecol Evol 20:328-36.

Parolo G, Rossi G, Ferrarini A, 2008. Toward improved species niche modelling: Arnica montana in the Alps as a case study. J Appl Ecol 45:1410-8.

Pavlovsky E, 1966. Natural nidality of transmissible diseases with special reference to the landscape epidemiology of zooanthroponoses. University of Illinois Press, Urbana, IL, USA.

Peterson AT, 2001. Predicting species' geographic distribution based on the ecological niche modeling. The Condor 103:599-605.

Peterson AT, 2003. Predicting the geography of species' invasions via ecological niche modeling. Q Rev Biol 78:419-33.

Phillips SJ, Anderson RP, Schapire RE, 2006. Maximum entropy modeling of species geographic distribution. Ecol Model 190:231-59.

Polop F, Provensal MC, Lamfri M, Scavuzzo M, Calderón G, Polop J, 2008. Environmental variables in the incidence of the Argentine Hemorrhagic Fever (AHR). Ecol Res 23:217-25.

Porcasi X, Rotela CH, Introini MV, Frutos N, Lanfri S, Peralta G, De Elia EA, Lanfri MA, Scavuzzo CM, 2012. An operative dengue risk stratification system in Argentina based on geospatial technology. Geospat Health 6:31-42.

Regis L, Monteiro AM, Melo-Santos MA, Silveira Jr JC, Furtado AF, Acioli RV, Santos GM, Nakazawa M, Carvalho MS, Ribeiro Jr PJ, de Souza WV, 2008. Developing new approaches for detecting and preventing Aedes aegypti population outbreaks: basis for surveillance, alert and control system. Mem I Oswaldo Cruz 103:50-9.

Rogers DJ, Randolph SE, 1991. Mortality rates and population density of tsetse flies correlated with satellite imagery. Nature 351:739-41.

Rogers DJ, Randolph SE, 1993. Distribution of tsetse and ticks in Africa: past, present and future. Parasitol Today 9:266-71.

Rossi GC, Almiron WR, 2004. [Clave ilustrada para la identificación de larvas de mosquitos de interés sanitario encontradas en criaderos artificiales en Argentina]. [Book in Spanish]. Fundación Mundo Sano, Buenos Aires, Argentina.

Rotela $\mathrm{CH}, 2012$. [Desarrollo de modelos e indicadores remotos de riesgo epidemiológico de dengue en Argentina]. [Book in Spanish]. National University of Córdoba, Córdoba, Argentina.

Rotela C, Fouque F, Lamfri M, Sabatier P, Introini V, Zaidenberg M, Scavuzzo C, 2007. Space-time analysis of the dengue spreading dynamics in the 2004 Tartagal outbreak, Northern Argentina. Acta Trop 103:1-13.

Rotela CH, Espinosa M0, Albornoz C, Lafaye M, Lacaux JP, Yves M, Tourre M, Vignolles CM, Scavuzzo CM, 2010. [Desarrollo de mapas predictivos de densidad focal de Aedes aegypti en la ciudad de Puerto Iguazú (Argentina), basados en información ambiental derivada de imágenes Spot 5 HRG1]. [Article in Spanish]. SELPER 30:24-33.

Seijo A, Romer Y, Espinosa M, Monroig J, Giamperetti S, Diego A, Antonelli L, 2009. Outbreak of indigenous dengue in the Buenos Aires metropolitan area. Experience of the F.J. Muniz Hospital. Medicina (B Aires) 69:593-600.

Siqueira-Junior JB, Maciel IJ, Barcellos C, Souza WV, Carvalho MS, Nascimento NE, Oliveira RM, Morais-Neto 0, Martelli CMT, 2008. Spatial point analysis based on dengue surveys at household level in central Brazil. BMC Public Health 8:361.

TDR/WHO, 2009. Dengue. Guidelines for diagnosis, treatment, preven- 
tion and control. World Health Organization (WHO) and the Special Programme for Research and Training in Tropical Diseases (TDR), Geneva, Switzerland.

Tran A, Deparis X, Dussart P, Morvan J, Rabarison P, Remy F, Polidori L, Gardon J, 2004. Dengue spatial and temporal patterns, French Guiana, 2001. Emerg Infect Dis 10:615-21.

Troyo A, Fuller D0, Calderon-Arguedas 0, Solano ME, Beier JC, 2009. Urban structure and dengue fever in Puntarenas, Costa Rica. Singap J Trop Geogr 30:265-82.

Trpis M, Hausermann W, 1986. Dispersal and other population parameters of Aedes aegypti in an African village and their possible significance in epidemiology of vector-borne diseases. Am J Trop Med Hyg 35:1263-79.
Vezzani D, Carbajo AE, 2008. Aedes aegypti, Aedes albopictus, and dengue in Argentina: current knowledge and future directions. Mem I Oswaldo Cruz 103:66-74.

Vezzani D, Rubio A, Velázquez SM, Schweigmann N, Wiegand T, 2005. Detailed assessment of microhabitat suitability for Aedes aegypti (Diptera: Culicidae) in Buenos Aires, Argentina. Acta Trop 95:123 31.

WHO, 2014. State of the art in the prevention and control of dengue in the Americas. World Health Organization, Geneva, Switzerland. Available from: http://iris.paho.org/xmlui/handle/123456789/31171

Wood BL, Beck LR, Washino RK, Hibbard KA, Salute JS, 1992. Estimating high mosquito-producing rice fields using spectral and spatial data. Int J Remote Sens 13:2813-26. 